\title{
REVIEW
}

\section{A global review of marine turtle entanglement in anthropogenic debris: a baseline for further action}

\author{
Emily M. Duncan ${ }^{1,2,3, *}$, Zara L. R. Botterell ${ }^{1, *}$, Annette C. Broderick ${ }^{1}$, \\ Tamara S. Galloway ${ }^{2}$, Penelope K. Lindeque ${ }^{3}$, Ana Nuno ${ }^{1}$, Brendan J. Godley ${ }^{1, * *}$ \\ ${ }^{1}$ Marine Turtle Research Group, Centre for Ecology and Conservation, University of Exeter, Penryn TR10 9FE, UK \\ ${ }^{2}$ Biosciences, College of Life and Environmental Sciences, Geoffrey Pope Building, University of Exeter, Stocker Road, \\ Exeter EX4 4QD, UK \\ ${ }^{3}$ Marine Ecology and Biodiversity, Plymouth Marine Laboratory, Prospect Place, West Hoe, Plymouth PL1 3DH, UK
}

\begin{abstract}
Entanglement in anthropogenic debris poses a threat to marine wildlife. Although this is recognised as a cause of marine turtle mortality, there remain quantitative knowledge gaps on entanglement rates and population implications. We provide a global summary of this issue in this taxon using a mixed methods approach, including a literature review and expert opinions from conservation scientists and practitioners worldwide. The literature review yielded 23 reports of marine turtle entanglement in anthropogenic debris, which included records for 6 species, in all ocean basins. Our experts reported the occurrence of marine turtles found entangled across all species, life stages and ocean basins, with suggestions of particular vulnerability in pelagic juvenile life stages. Numbers of stranded turtles encountered by our 106 respondents were in the thousands per year, with $5.5 \%$ of turtles encountered entangled; $90.6 \%$ of these dead. Of our experts questioned, $84 \%$ consider that this issue could be causing population level effects in some areas. Lost or discarded fishing materials, known as 'ghost gear', contributed to the majority of reported entanglements with debris from land-based sources in the distinct minority. Surveyed experts rated entanglement a greater threat to marine turtles than oil pollution, climate change and direct exploitation but less of a threat than plastic ingestion and fisheries bycatch. The challenges, research needs and priority actions facing marine turtle entanglement are discussed as pathways to begin to resolve and further understand the issue. Collaboration among stakeholder groups such as strandings networks, the fisheries sector and the scientific community will facilitate the development of mitigating actions.
\end{abstract}

KEY WORDS: Conservation · Entanglement - Ghost fishing · Marine debris · Plastic pollution · Sea turtle $\cdot$ Strandings

\section{INTRODUCTION}

\section{Marine plastic pollution}

Anthropogenic materials, the majority of them plastic, are accumulating on the surface of the oceans, in the water column and on the seabed (Thompson et al.

\footnotetext{
*These authors contributed equally to this work
}

${ }^{* *}$ Corresponding author: b.j.godley@exeter.ac.uk
2004). The durability of plastic means that it may persist for centuries (Barnes et al. 2009). It is estimated that 4.8 to 12.7 million tonnes of plastic waste could be entering the marine environment annually (Jambeck et al. 2015). Over 700 marine species have been demonstrated to interact with marine plastic pollution (Gall \& Thompson 2015), which presents a risk to ani-

(C) The authors 2017. Open Access under Creative Commons by Attribution Licence. Use, distribution and reproduction are unrestricted. Authors and original publication must be credited. 
mals through ingestion, entanglement, degradation of key habitats and wider ecosystem effects (Nelms et al. 2016). Megafauna such as marine turtles with complex life histories and highly mobile behaviour are particularly vulnerable to its impacts (Schuyler et al. 2014).

\section{Entanglement in marine litter}

Entanglement in plastic debris is recognised as a major risk for many marine species (Laist 1987, Vegter et al. 2014). This has become sufficiently high profile that the European Union's Marine Strategy Framework Directive (MSFD) Technical Subgroup on Marine Litter has announced that it will develop a dedicated monitoring protocol for its next report (MSFD GES Technical Subgroup on Marine Litter 2011). Entanglement has the potential to cause a range of fatal and non-fatal impacts such as serious wounds leading to maiming, amputation, increased drag, restricted movement or choking (Votier et al. 2011, Barreiros \& Raykov 2014, Lawson et al. 2015).

\section{Types of marine debris causing entanglement}

The debris causing this entanglement falls into 2 broad categories. Firstly, hundreds of tons of fishing gear are lost, abandoned or discarded annually, forming 'ghost gear' which passively drifts over large distances, sometimes indiscriminately 'fishing' marine organisms (Macfadyen et al. 2009, Wilcox et al. 2013). This gear is commonly made of non-biodegradable synthetic material that will persist in the marine environment, potentially become biofouled by marine organisms and act as a fish aggregating device (FAD), attracting both grazers and predators such as marine turtles (Filmalter et al. 2013, Wilcox et al. 2013). It is important to distinguish here between 'entanglement' and 'bycatch'. Bycatch can be defined as unselective catch of either unused or unmanaged species during fishing, with a particular focus on 'active' gear, whereas ghost gear can be defined as equipment of which the fisher has lost operational control (Smolowitz 1978, Davies et al. 2009). Therefore, here we consider animals caught in passive ghost fishing gear as entangled, not bycaught. Secondly, there have also been reports of entanglement in litter from land-based sources (Chatto 1995, Bentivegna 1995, Santos et al. 2015). In this review we do not include bycaught turtles - only those that have become entangled in passive anthropogenic debris such as ghost gear or land-based debris.

\section{Current knowledge gaps regarding turtle entanglement}

Despite turtle entanglement being recognised as one of the major sources of turtle mortality in northern Australia and the Mediterranean, there is a quantitative knowledge gap with respect to the entanglement rates and possible implications in terms of global populations (Casale et al. 2010, Wilcox et al. 2013, Camedda et al. 2014, Gilman et al. 2016). A recent literature review by Nelms et al. (2016) returned only 9 peer-reviewed publications on marine debris entanglement and turtles (Bentivegna 1995, Chatto 1995, López-Jurado et al. 2003, Casale et al. 2010, Santos et al. 2012, Jensen et al. 2013, Wilcox et al. 2013, 2015, Barreiros \& Raykov 2014). Of these, 7 were focused on ghost fishing gear, highlighting the distinct lack of knowledge of entanglement in debris from landbased sources. Even fewer of these studies focused on the potential variable susceptibility among life stages or species, with only one paper, Santos et al. (2012), reporting that the majority of entangled olive ridley turtles Lepidochelys olivacea on the Brazilian islands of Fernando de Noronha and Atol das Rocas were sub-adults and adults.

\section{Research rationale in terms of marine turtles and pollution}

In terms of global research priorities for sea turtle conservation and management, understanding the impact of pollution is considered of high importance (Hamann et al. 2010, Rees et al. 2016). To evaluate this effectively, the impact of anthropogenic debris, specifically, must be considered at a species and population level. Additionally, it is important to understand the variation in entanglement rates among species and life stages to better evaluate vulnerability and the frequency of interactions with different debris types (Nelms et al. 2016). Once these have been established, opportunities for delivering effective education and awareness can be given or other mitigation planned (Vegter et al. 2014).

Here, we define marine turtle entanglement as 'the process under which a marine turtle becomes entwined or trapped within anthropogenic materials.' We sought to include discarded fishing gear (ghost fishing) as well as land-based sources. The aim of this study was to (1) review existing, and obtain new, reports of the occurrence and global spatial distribution of marine turtle entanglement; (2) gain insights into patterns of species, life stage and 
debris type involved across entanglement cases; and (3) glean an insight into the change in prevalence of marine debris entanglement over time. To address these, a mixed methods approach was employed, involving a literature review and an elicitation of expert opinions. Given the difficulty of acquiring robust standardised data, this review is intended to highlight the value of mixed methods as a first step to understand complex conservation issues, and to provide suggestive yet relevant indications as to the scale of the threat of entanglement to marine turtles.

\section{MATERIALS AND METHODS}

\section{Literature review}

In January 2016 and again in June 2017 (during the manuscript review process), all relevant literature was reviewed that may have contained records of marine turtle entanglement. ISI Web of Knowledge, Google Scholar and the Marine Turtle Newsletter (www.seaturtle.org) were searched for the terms 'entanglement', 'entrapment', 'ensnare' or 'ghost fishing' and 'turtle'. The first 200 results were viewed, with results very rarely fulfilling the criteria after the first 20; spurious hits were ignored and all relevant references were recorded and investigated.

\section{Elicitation of expert opinions}

During the period 1-30 April 2016, an online questionnaire survey was conducted to investigate 3 main topics of interest: (1) the occurrence and global spatial distribution of sea turtle entanglement; (2) species, life stage and debris type involved; and (3) the change in entanglement prevalence over time. A total of 20 questions requiring both open and closed responses from a range of experts were used to obtain insight into the scale of marine turtle entanglement. We clearly explained to the respondents the definition of 'marine turtle entanglement' specific to this study. Grid-like responses and Likert scales, offering potential answers from a range of ordinal options, were used to aid in achieving a quantitative assessment of the issues (Elaine \& Seaman 2007) (see Box S1 in the Supplement at www.int-res.com/ articles/suppl/n034p431_supp.pdf).

Potential participants for this questionnaire were identified from lead authorship of papers compiled in the recent review on the effects of marine plastic debris on turtles from Nelms et al. (2016), and our review due to their involvement in research into marine debris. From reviewing the few published reports, it was apparent that governmental stranding networks, sea turtle rescue and rehabilitation centres and conservation projects may also hold many unpublished records of entanglement occurrence. A comprehensive list of such organisations from seaturtle.org (www.seaturtle.org/groups/; accessed 24 March 2016) was used to find more expert contacts to participate in the questionnaire. Additionally, considering the aim of attaining an appropriate number of respondents while avoiding potential sampling biases due to researchers' personal networks and perceptions about the issue (Newing 2011), we employed respondent-driven sampling; this purposive sampling approach involves requesting those directly contacted to recruit additional participants among colleagues, peers and other organisations that may have knowledge of additional records of marine turtle entanglement.

From this first questionnaire, an initial report was produced and sent to the expert respondents ( $\mathrm{n}=$ 106) to share the results and thoughts that arose from the first questionnaire. This included 8 initial figures produced from the data given by respondents in the original questionnaire to aid feedback of our results (these were draft versions of Figs. 2, 3 \& 4). Following this, during the period 24 May to 30 June 2016, a follow-up questionnaire survey was conducted with the expert participants of the first questionnaire survey who were then invited to comment and answer 10 open and closed questions (see Box S2 in the Supplement). This aimed to further understand the challenges, future requirements (both research and priority actions) and perceptions of the likelihood of population level effects of marine turtle entanglement. In this second questionnaire, respondents were asked to comment on our initial results and to provide suggestions on future knowledge gains and actions. Their answers were categorised using an inductive approach; summary themes were identified through the process of directly examining the data (Elo \& Kyngäs 2008), instead of having predefined categories.

\section{RESULTS}

\section{Literature review}

Our literature search yielded 23 reports regarding entanglement in multiple species of marine turtles, the majority of which were peer-reviewed publica- 
tions $(\mathrm{n}=17$ ) with additional grey literature reports $(\mathrm{n}=6)$. Species included loggerhead Caretta caretta $(\mathrm{n}=7)$, green Chelonia mydas $(\mathrm{n}=7)$, leatherback Dermochelys coriacea ( $\mathrm{n}=5)$, hawksbill Eretmochelys imbricata $(\mathrm{n}=5)$, olive ridley Lepidochelys olivacea $(\mathrm{n}=9)$ and flatback Natator depressus $(\mathrm{n}=2)$. There were no records for Kemp's ridley Lepidochelys kempii (Table 1). Of these publications, 18 reported entanglement due to ghost fishing or fisheries materials and 7 recorded entanglement in landbased plastic debris; 7 publications reported the size range and life stage of the entangled turtles. These publications highlighted a range of impacts of entanglement, such as serious wounds leading to maiming, amputation or death, increased drag, restricted movement or choking that were further illustrated by photographs from collaborating experts (Fig. 1).
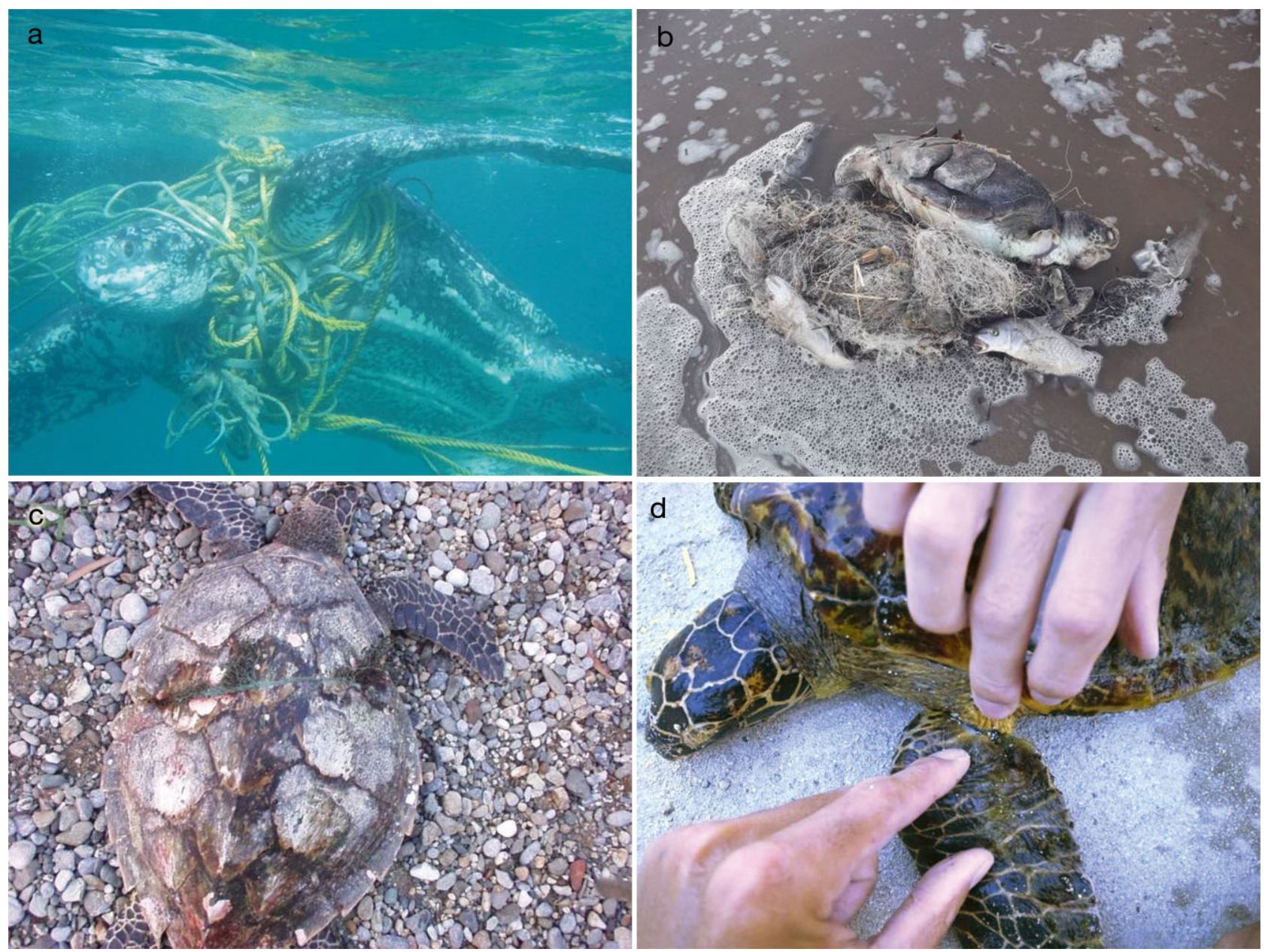

Fig. 1. Impacts of marine turtle entanglement: (a) live leatherback turtle entangled in fishing ropes which increases drag, Grenada 2014 (photo: Kate Charles, Ocean Spirits); (b) drowned green turtle entangled in ghost nets in Uruguay (photo: Karumbe); (c) live hawksbill turtle entangled in fishing material constricting shell growth, Kaeyama Island, Japan 2001 (photo: Sea Turtle Association of Japan); (d) live hawksbill turtle with anthropogenic debris wrapped around front left flipper constricting usage of limb which could lead to amputation and infection, Kaeyama Island, Japan 2015 (photo: Sea Turtle Association of Japan). All photos used with express permission 


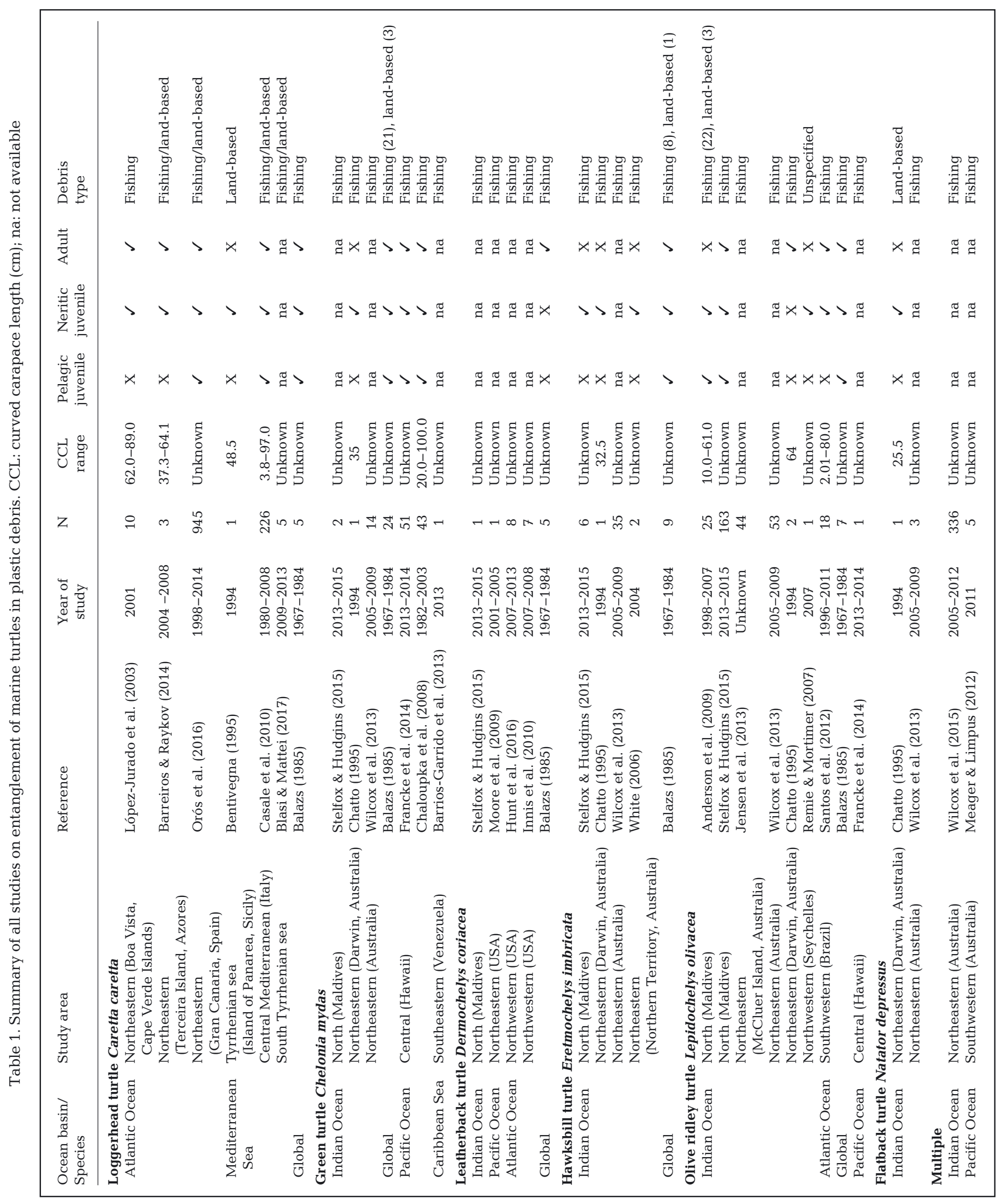


range in the number of annual stranding cases in their respective study sites (annual maxima given in the survey; mean $\pm \mathrm{SE}=239.9 \pm 71.7$, range $=0$ to 4100 , $\mathrm{n}=97$ ) but in total, through addition of the respondents' answers, they are responsible for attending an estimated 23000 stranded turtles $\mathrm{yr}^{-1}$. Respondents also generally had many years of experience dealing with and reporting marine turtle strandings (range $=2$ to $42 \mathrm{yr}$, mean $\pm \mathrm{SE}=15.6 \pm 1.1, \mathrm{n}=98$ ), confirming them as having relevant experience to answer the survey. The second follow-up questionnaire sent to all respondents $(n=106)$ received 63 responses with respondents from 31 countries.

\section{Rates of entanglement}

A majority of respondents $(84.3 \%$; $=101)$ had encountered cases in which turtles were entangled in anthropogenic debris. When broken down by species, the proportion of stranded turtles that were entangled did not differ significantly (Kruskal-Wallis: $\chi^{2}=4.59, \mathrm{df}=6, \mathrm{p}=0.59$ ) (Fig. 2a). There was a low percentage incidence for all species, with the grand median rate of $5.5 \%$, although there was considerable inter- and intraspecific variation, with incidences in different responses ranging from 0 to $95.5 \%$. In terms of the proportion of marine turtles alive when found entangled, there were significant interspecific differences (Kruskal-Wallis: $\chi^{2}=19.62$, df $=6, \mathrm{p}=$ 0.003 ). The proportion found alive (grand median $=$ $9.4 \%)$ was significantly higher in green $(25.5 \%)$ and loggerhead $(15.5 \%)$ turtles than in all other species (5.5\%) (Fig. 2b).

Entanglement rates also differed amongst life stages for each species. Whilst respondents indicated that all life stages of each species had been affected by entanglement, the results suggested adults were most impacted in leatherback and olive ridley turtles, whereas for the remaining species respondents indicated a higher rate of entanglement in juveniles (pelagic and neritic; Fig. 3).

When considering this issue over time (over the last $10 \mathrm{yr})$, a similar proportion of respondents $(35.8 \%$ of 106) thought the prevalence of entanglement had increased or remained the same, while the remainder thought it had decreased $(8.5 \%)$ or were unsure $(19.8 \%)$. Among those respondents that noted an increase, some $(\mathrm{n}=4)$ suggested that this may be caused by an increase in reporting and awareness, while others $(n=9)$ indicated the development of coastal fishing activities might be a factor. When asked to consider a shorter time period (the last $5 \mathrm{yr}$ ),
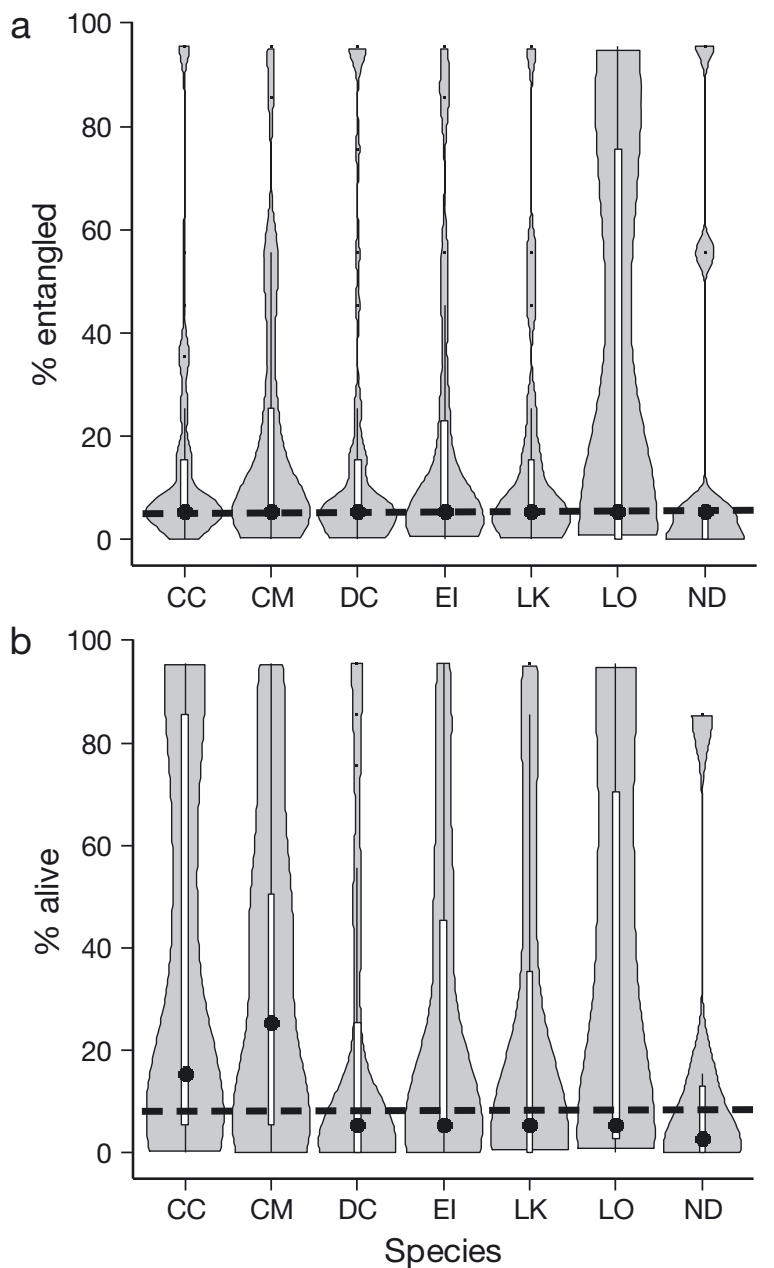

Fig. 2. Inter-species comparison of the proportion of: (a) stranded individuals found entangled and (b) individuals found alive when discovered entangled. Violin plots show the kernel density of data at different values. Median (black dot) with interquartile range boxplot (black/white) and grand median (black dashed line). Turtle species abbreviations: CC: loggerhead Caretta caretta; CM: green Chelonia mydas; DC: leatherback Dermochelys coriacea; EI: hawksbill Eretmochelys imbricata; LK: Kemp's ridley Lepidochelys kempii; LO: olive ridley Lepidochelys olivacea; ND: flatback turtle Natator depressus

the majority of respondents believed that the prevalence of entanglement they had experienced had remained stable $(51.9 \%)$, whilst the others thought it had increased $(29.2 \%)$, decreased $(3.8 \%)$ or were not sure $(15.1 \%)$.

\section{Entanglement materials}

The majority of entanglements recorded were with lost/discarded fishing gear (Fig. 4). A clear distinction was made between 'active' and 'lost/discarded' 


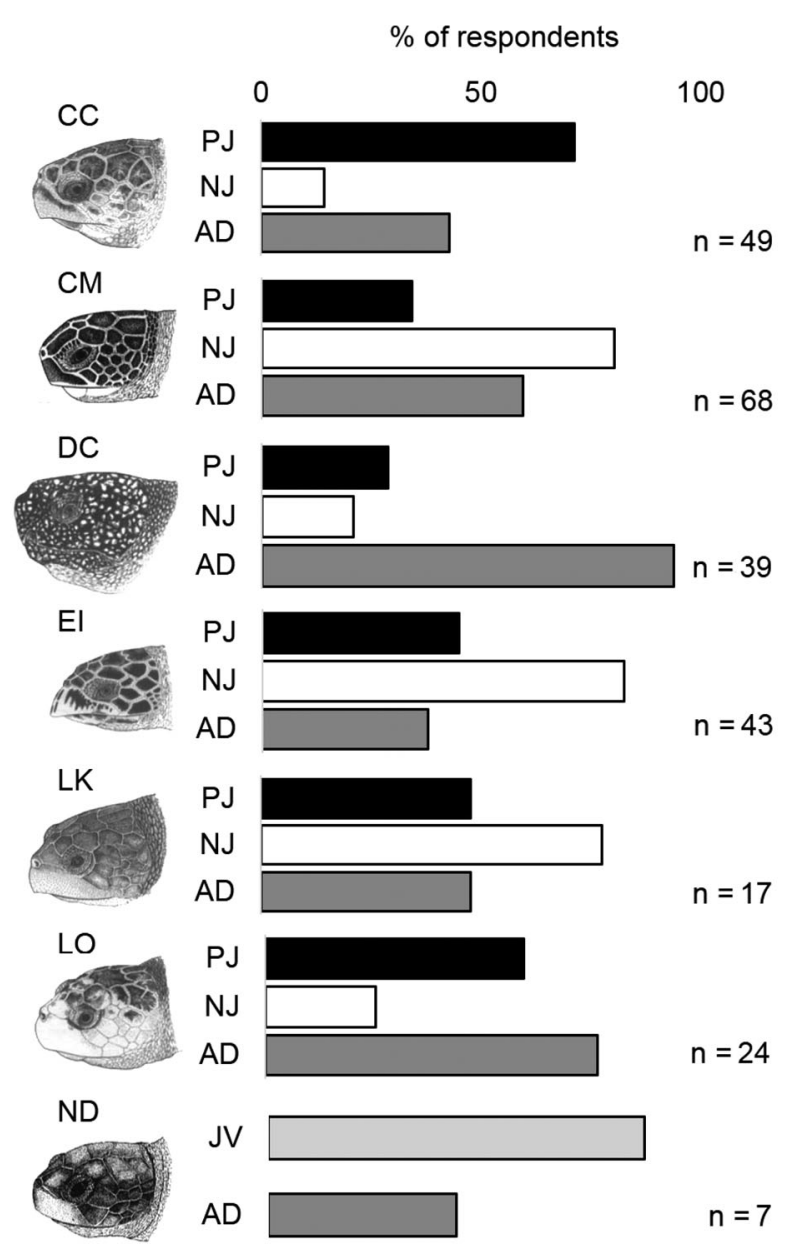

Fig. 3. Inter-specific comparison of the breakdown of entangled sea turtle species by life stage. Black: pelagic juveniles (PJ); white: neritic juveniles (NJ); light grey: juveniles (JV); dark grey: adults (AD); see Fig. 2 for species abbreviations. Flatback turtles were only categorised into juvenile or adult classes with advice from species experts. Sea turtle skull figures used with permission of WIDECAST; original artwork by Tom McFarland

fishing gear to try and separate incidents due to bycatch and subsequent stranding from those caused by ghost fishing. The number of responses on the occurrence of ghost fishing (GF) through discarded fishing debris (rope, net and line) was generally slightly higher than for bycatch (BC) through active gear.

A smaller percentage of respondents specified cases of turtle entanglement in land-based sources, from polythene sheeting $(\mathrm{n}=71)$, woven sacks $(\mathrm{n}=$ 72 ) and non-fishing rope/twine $(n=68)$. But in only a few incidences were these said to be common occurrences (polythene sheeting $[\mathrm{n}=3]$, woven sacks $[\mathrm{n}=4]$, non-fishing rope/twine $[\mathrm{n}=7]$ ). Respondents were asked to comment on the occurrence of 'other'

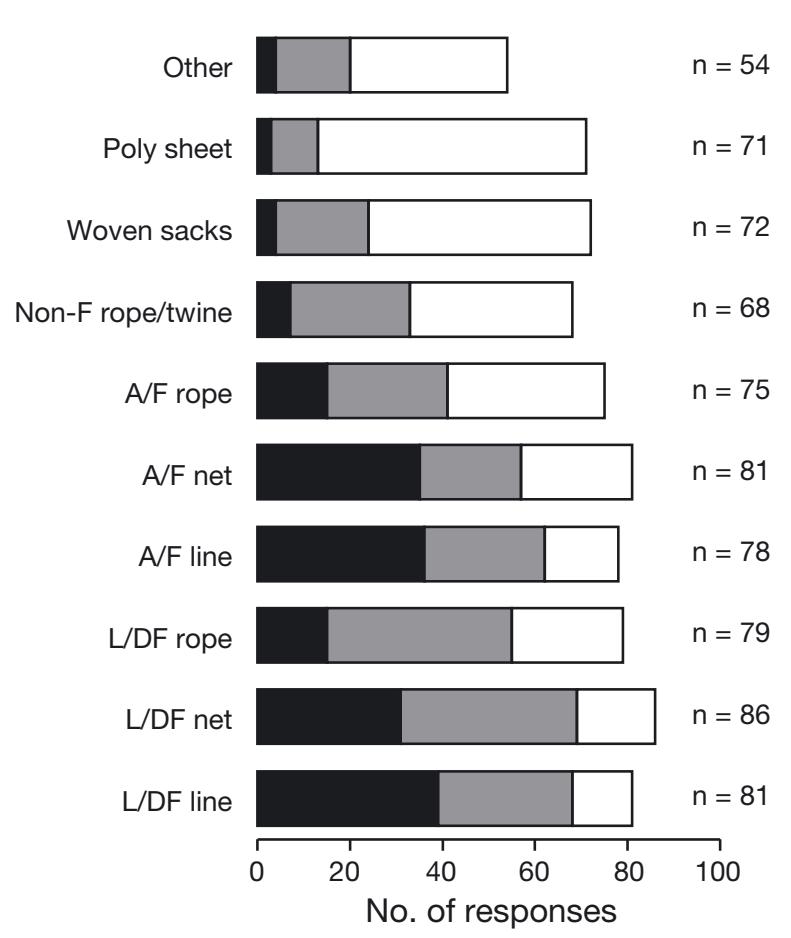

Fig. 4. Entangling materials. L/DF: lost/discarded fishing; A/F: active fishing; Non-F: non fishing; Poly sheet: polyethylene sheeting. Black: common $(10 \%$ or more of cases); grey: sometimes (less than $10 \%$ of cases); white: never. Not all participants categorised each material; total number of responses for each material shown on the right of the graph

entangling materials $(\mathrm{n}=54)$ and to provide examples $(n=20)$ that caused turtle entanglement. This included debris from land-based sources (plasticballoon string, canned drink '6-pack' rings, kite string, plastic chairs, plastic packaging straps, wooden crates and weather balloons) and debris from other maritime activities (boating mooring line, anchor line and discarded seismic cable).

Scale of issue

In order to obtain further insights into the potential scale of this issue, respondents to the second survey were asked whether they thought entanglement in anthropogenic debris is causing population-level effect in marine turtles. Of the 63 respondents, $84.1 \%$ thought that this was probable, very likely or definite (see Fig. S1 in the Supplement). There was no significant difference in scaled responses by ocean basin (Kruskal-Wallis: $\chi^{2}=1.82, \mathrm{df}=4, \mathrm{p}=0.77$ ). In order to assess the relative importance of different threats according to experts, we also sought the experts' opinions on how they thought entanglement in anthro- 
pogenic debris compared to other threats to marine turtles (i.e. 'plastic ingestion', 'oil pollution', 'fisheries bycatch', 'direct exploitation' and 'climate change'). Although between 6.35 and $25.4 \%$ were unsure, there was a strong opinion that plastic ingestion and fisheries bycatch were greater threats, and that oil pollution, climate change and direct exploitation were less severe threats than entanglement (Fig. 5).

\section{Challenges, priority actions and research needs}

Respondents to the second survey converged on a limited number of themes when considering the challenges, research needs and priority actions within marine turtle entanglement. The challenges to addressing the issue (115 suggestions) could be grouped into 5 major categories: law and enforcement $(23.5 \% ; \mathrm{n}=27)$; sources and spatial extent of entanglement materials $(24.3 \%$; $\mathrm{n}=28)$; education and innovation $(24.3 \% ; \mathrm{n}=28)$; understanding the full extent of the threat $(18.3 \% ; \mathrm{n}=21)$; and human response to entangled turtles $(9.6 \% ; \mathrm{n}=11)$ (Table 2$)$. Seven major research areas were suggested by respondents (91 suggestions): more specific reporting and monitoring or a common database $(23.1 \%$; $\mathrm{n}=$ 21); mapping the threat/spatio-temporal hotspots $(31.9 \% ; \mathrm{n}=29)$; identifying entanglement materials and sea turtle interactions $(24.2 \% ; \mathrm{n}=22)$; understanding post-release mortality and physical effects $(3.3 \% ; \mathrm{n}=3)$; socio-economic impacts $(4.4 \% ; \mathrm{n}=4)$; innovation of new replacement materials $(6.6 \% ; \mathrm{n}=$ 6); and demographic risk assessments $(6.6 \% ; \mathrm{n}=6)$ (Table 3$)$. Priority actions ( $\mathrm{n}=121$ suggestions) that respondents believe would help reduce turtle entanglement were grouped into 5 major areas: education/stakeholder engagement $(31.4 \% ; \mathrm{n}=38)$; fisheries management and monitoring $(26.4 \% ; \mathrm{n}=32)$; research $(5 \% ; \mathrm{n}=6)$; law and enforcement $(20.7 \%$; $\mathrm{n}=25)$; and development of alternative materials and methods $(16.5 \% ; \mathrm{n}=20)$ (Table 4$)$.

\section{DISCUSSION}

\section{Global distribution}

Our review and elicitation of expert opinions demonstrate that marine turtle entanglement is an issue operating at a global scale, occurring in all species, throughout their geographic range. We sought to answer key knowledge gaps surrounding the issue of turtle entanglement in marine debris as previously

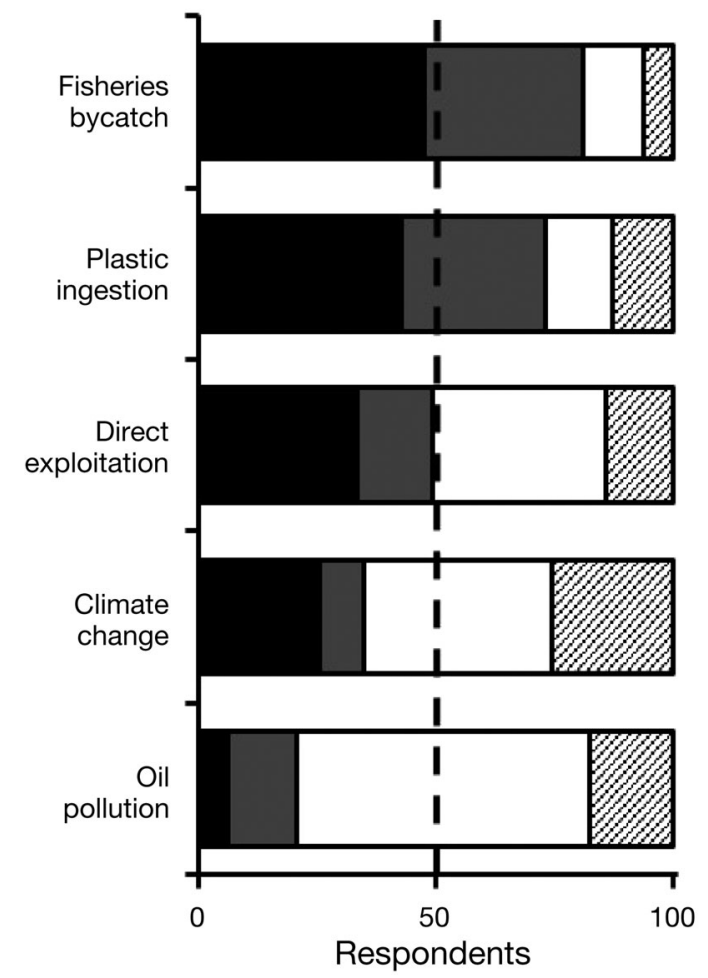

Fig. 5. Responses to comparison of other threats faced by marine turtles compared to entanglement $(\mathrm{n}=63)$. Black: greater than entanglement; grey: similar threat; white: less than entanglement; striped: unsure

highlighted by Vegter et al. (2014) and Nelms et al. (2016). Difficulties in investigating these knowledge gaps are in part due to a lack of robust data. This highlights the importance of using mixed methods to access expert opinion to gain an insight into this global threat. The growing use of expert knowledge in conservation is driven by the need to identify and characterise issues under limited resource availability, and the urgency of conservation decisions (Martin et al. 2012).

Acknowledging the incomplete coverage of our estimates, given the mean estimated number of strandings and mortality rates, in the order of 1000 turtles die annually as a result of entanglement in the areas monitored by our respondents. These levels are likely a profound underestimation of the scale of this issue as the coverage of these actors is far from comprehensive. Second, it is well known that not all dead turtles strand (Epperly et al. 1996, Sasso \& Epperly 2007), especially small and pelagic animals, and there can also be decay of entangled animals. Additionally, some of our respondents commented that detection of stranded animals may be further confounded due to take of stranded animals for human consumption. 


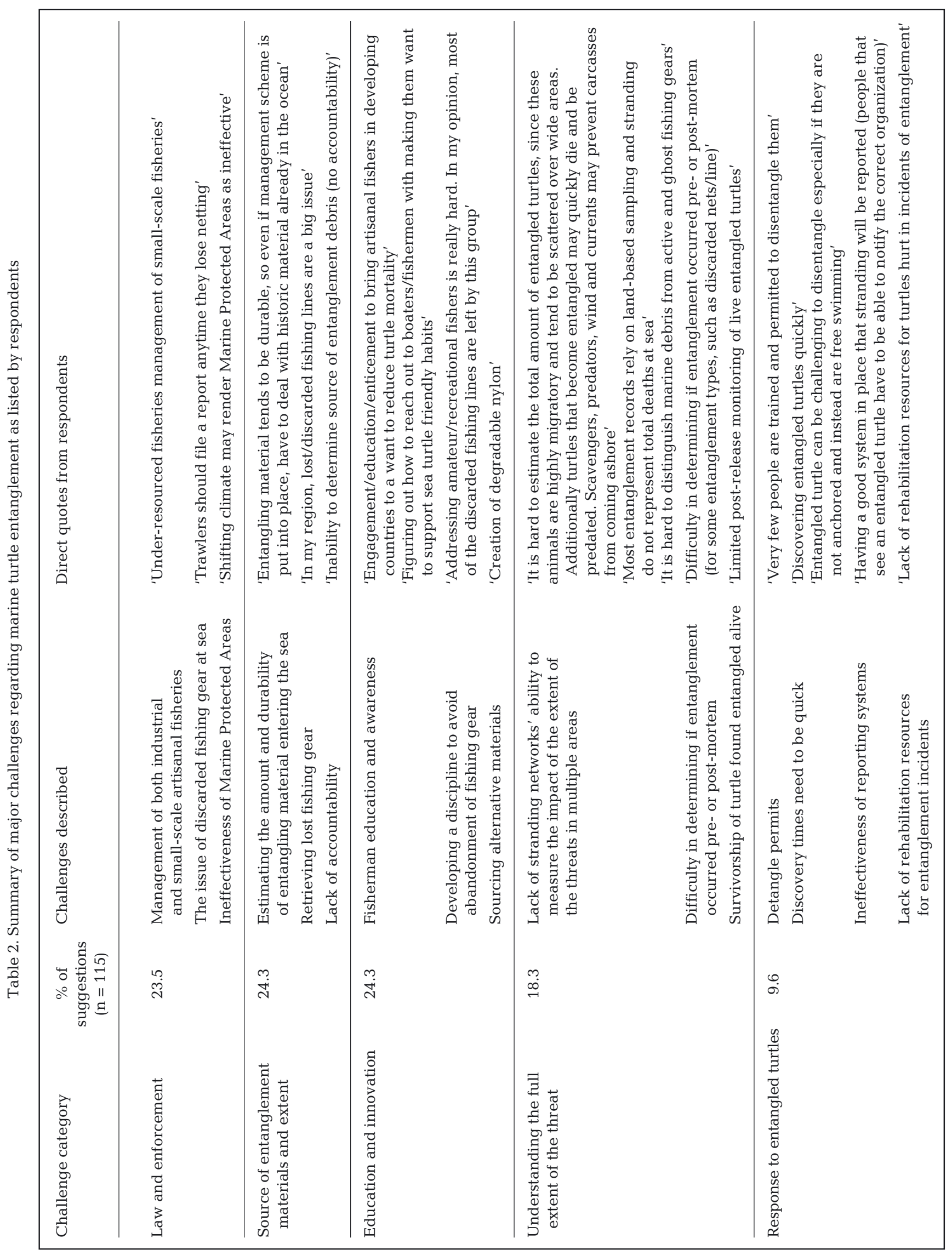




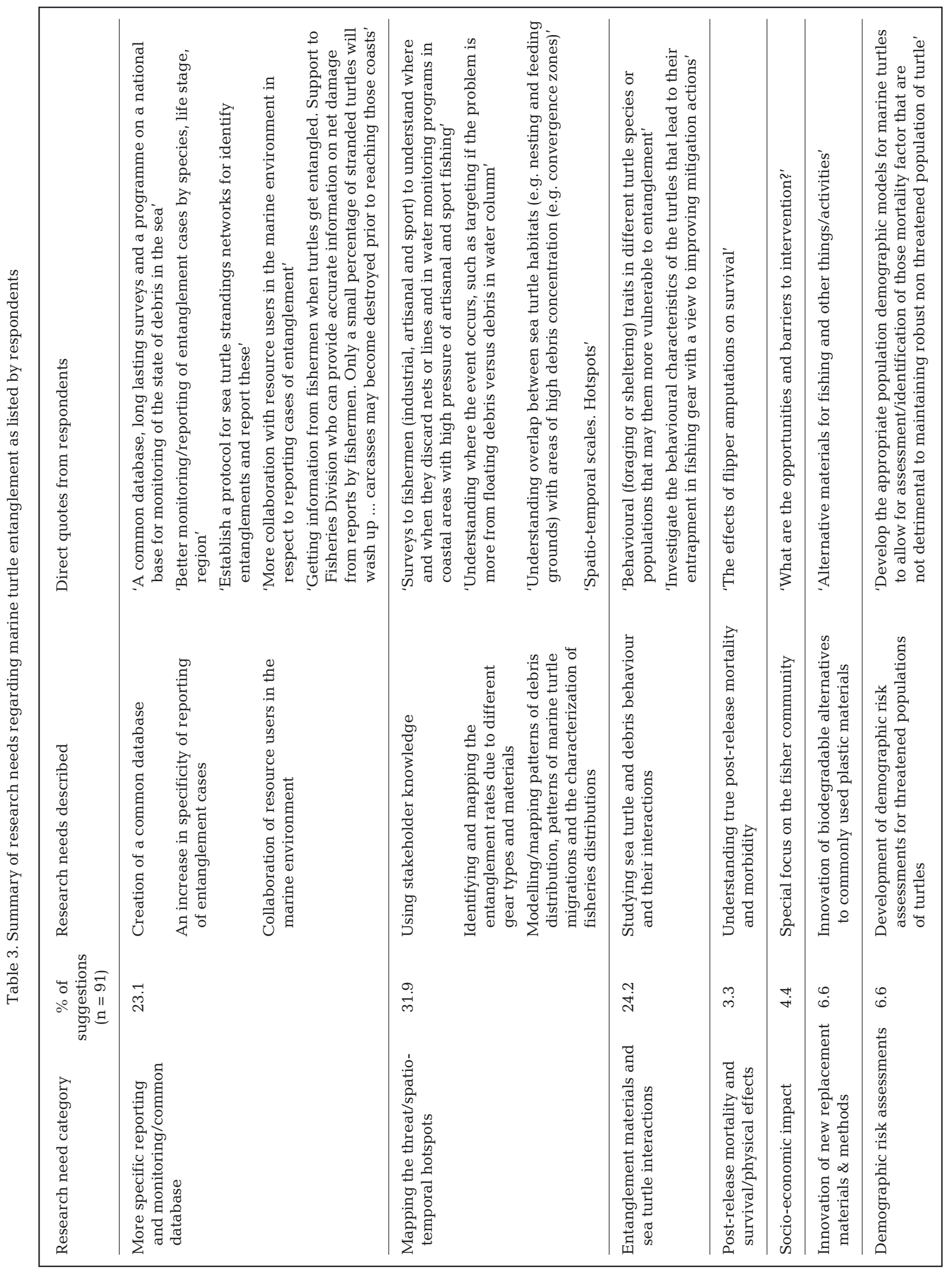




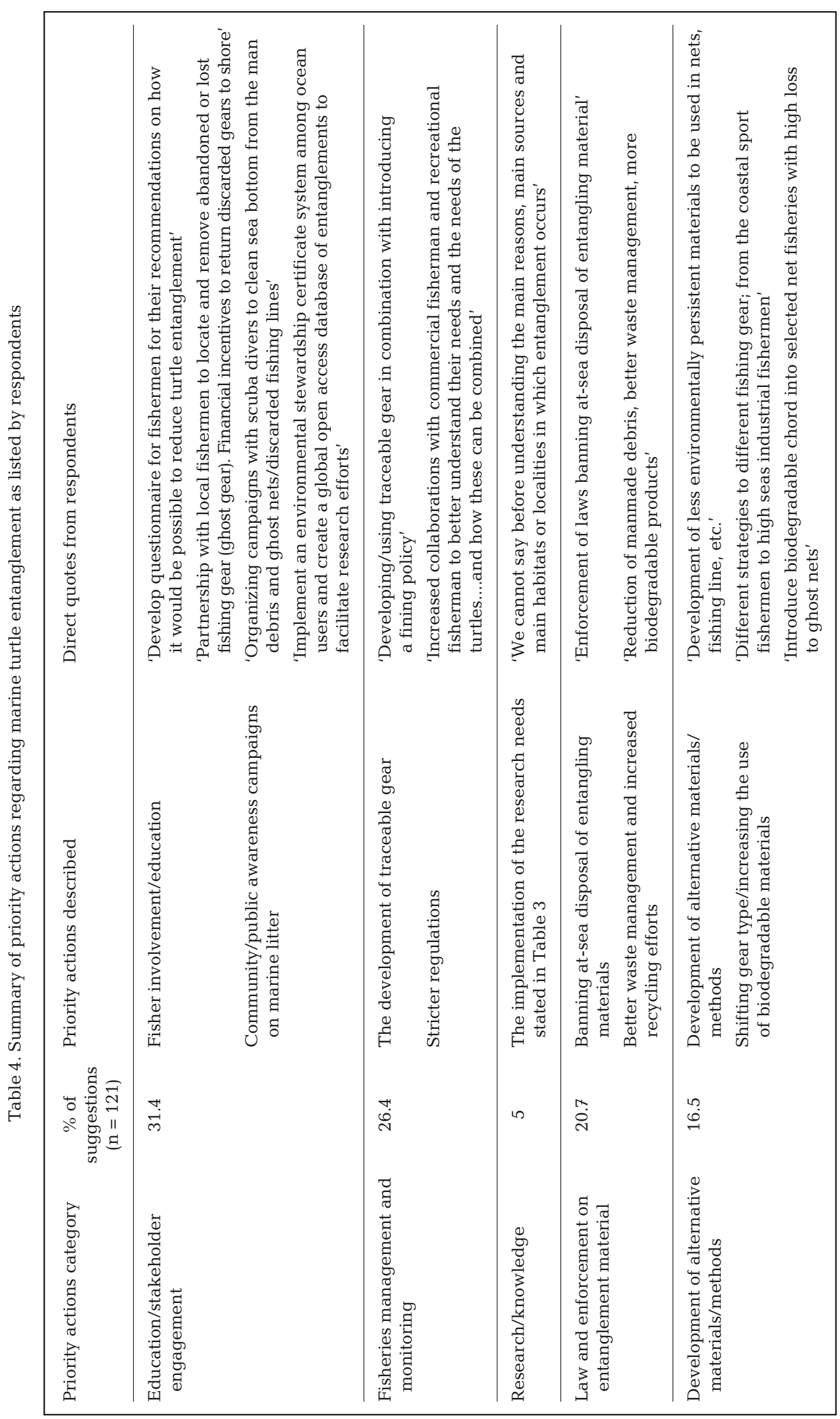




\section{Species differences}

Although there was no interspecific difference in the incidence of entanglement, most peer-reviewed publications featured olive ridley turtles, with some experts reporting high incidences of entanglement for this species. Stelfox et al. (2016) noted that olive ridley turtles accounted for the majority of sea turtles identified as entangled $(68 \% ; \mathrm{n}=303)$, and this could be for the following reasons. Firstly, this species, which often exhibits mass nesting in the hundreds of thousands of individuals, is highly numerous, and at particularly high densities in some areas, leading to entanglement hotspots (Jensen et al. 2006, Koch et al. 2006, Wallace et al. 2010a). Secondly, the olive ridley forages along major oceanic fronts which are known to aggregate marine debris (Polovina et al. 2004, McMahon et al. 2007). Finally, their generalist feeding behaviour potentially attracts them to feed opportunistically on biofouled marine debris such as ghost gear (Stelfox et al. 2016).

\section{Life stages}

Entanglement was reported to occur in all life stages (pelagic juveniles, neritic juveniles and adults) across all species (the exception being flatback turtles which have no pelagic juveniles; Hamann et al. 2011). Perhaps of greatest concern is the signal of high entanglement incidence in the pelagic juvenile stage: despite the general inaccessibility of sampling this life stage, they are still appearing as stranded entangled. The currents that transport hatchlings to oceanic convergence zones are also now recognised as concentrating floating anthropogenic debris, creating the capacity for an ecological trap for these young turtles, whether it be through ingestion or entanglement (Nelms et al. 2016, Ryan et al. 2016). Many respondents considered that entanglement could be having a population level effect; a distinct possibility if this there is a large impact on this cryptic life stage and on pelagic foraging adults (Mazaris et al. 2005).

\section{Entangling materials}

Respondent data highlighted that the majority of entanglements were the result of fishery-based material and other maritime activities. The issue of ghost fishing featured highly, with numerous responses reporting entanglement within lost/discarded gear. This gear is often lost, abandoned or discarded when it becomes derelict, attracting scavengers and acting as FADs (Gilman 2011). Subsequently, species such as marine turtles become entangled within the gear, perhaps encouraged by this process of 'selfbaiting' (Matsuoka et al. 2005).

\section{Change in fishing practice}

The issue of ghost fishing appears to have worsened since the 1950s, as the world's fishing industries have replaced their gear, which was originally made of natural fibres such as cotton, jute and hemp, with synthetic plastic materials such as nylon, polyethylene and polypropylene. Manufactured to be resistant to degradation in water means that once lost, it can remain in the marine environment for decades (Good et al. 2010). Furthermore, there has also been a shift in the type of synthetic nets being selected; for example, fishers in part of Southeast Asia now increasingly favour superfine nets. Although this can help increase catches, the twine thinness means that they break easily and are difficult to repair once damaged (Stelfox et al. 2016). The incidences of entanglement caused by this form of pollution in our expert surveys indicates that this source of mortality for marine turtles mirrors that in marine mammals and sea birds, which has increased substantially over the last century (Tasker et al. 2000, Good et al. 2010, McIntosh et al. 2015).

\section{Differentiation from bycatch}

It is quite plausible that ghost fishing may be working synergistically alongside bycatch, but because of its more cryptic nature this means that understanding its role in marine turtle mortality is much more difficult. Bycatch is better understood. For example, the analysis of catch rates in the Mediterranean allowed for the estimation of 132000 captures and 44000 incidental deaths per year (Casale 2011). Likewise, cumulative analysis of catch rates in US fisheries estimated a total of 71000 annual deaths prior to the establishment of bycatch mitigation methods. Since these measures were implemented, mortality estimates are $\sim 94 \%$ lower (4600 deaths $\mathrm{yr}^{-1}$ ) (Finkbeiner et al. 2011). This highlights the importance of informed estimates to monitor the success of mitigation methods. In addition to bycatch mortality estimates, spatial and temporal patterns of bycatch inci- 
dences can be identified. Using onboard observer data, Gardner et al. (2008) found seasonal changes in catch distributions of loggerhead and leatherback turtles in the North Atlantic, with patterns of spatial clustering from July to October. Analysed on a global scale, Wallace et al. (2010b) were able to highlight region-gear combinations requiring urgent action such as gillnets, longlines and trawls in the Mediterranean Sea and eastern Pacific Ocean. Generating such estimates of catch rates and spatial/temporal patterns for entanglement are not yet possible due to the lack of quantitative information.

Land-based plastic entanglements

The domination of fisheries-based materials in the results does not mean that land-based plastics are not a source of entanglement. The increased input of plastic debris from terrestrial run-off means that these interactions are only likely to increase (Jambeck et al. 2015). Our literature search and 'other' materials stated by respondents contained a variety of items causing entanglement that could be decreased by reduction of use, replacement with more degradable alternatives and better waste management and recycling. The prevalence of these materials in the marine environment will very much depend on future waste governance, especially in those countries that generate the most plastic waste (Jambeck et al. 2015). A future technological solution which is currently being investigated or adopted in high plastic-generating countries such as Thailand and India is the pyrolysis of plastics. This process produces fuel from waste plastic, a better alternative to landfill and a partial replacement of depleting fossil fuels (Wong et al. 2015).

\section{Caveats}

It is important to recognise the biases associated with using stranding animals for data collection. Within and between stranding sites there are differences in turtle foraging ecology, life stages and proximity to human habitation (Bolten 2003, Rees et al. 2010), and therefore they are exposed to different levels and types of potential entangling materials. Individual turtles therefore may not represent a homogeneous group in terms of entanglement occurrence within that population (Casale et al. 2016). Additionally, recovered carcasses represent an unknown fraction of at-sea mortalities, with physical oceanography (e.g. currents) and biological factors (e.g. decomposition) affecting the probability and location of carcass strandings (Hart et al. 2006). However, examining reports of stranded animals represents a vital opportunity for research and can provide insights into the impacts of anthropogenic threats which would otherwise go undetected (Chaloupka et al. 2008, Casale et al. 2010). In addition, stranding information aids with the assessment of harder-to-access life stages, yielding key information on the risk to specific resident populations and contributing to building a worldwide perspective for conservation issues (Chaloupka et al. 2008, Casale et al. 2016). Indeed, this was the aim of our study: using stranding data from expert respondents to gain an initial indication of the estimated magnitude of this threat.

Surveying experts can be a powerful tool for obtaining insights on particular topics not widely known by others (Martin et al. 2012). Expert knowledge and opinions may be the result of training, research, skills and personal experience (Burgman et al. 2011a). In this study, we sought the opinions of conservation scientists and practitioners with experience in marine turtle entanglement and strandings. Due to the purposive sampling nature of our approach, we aimed to identify people with relevant experiences instead of focusing on obtaining a random selection of representatives; this is a widely used practice when undertaking social surveys that focus on particular subgroups or specialists (Newing 2011). Nevertheless, expert knowledge and opinions are also known to be subject to biases, including overconfidence, accessibility and motivation (see e.g. Burgman et al. 2011b and Martin et al. 2012). In the absence of empirical data to validate our findings, this remains as simply suggestive but nevertheless relevant information in terms of identifying a potentially important conservation issue and providing relative indications of the scale of entanglement as a threat to sea turtles.

\section{Future actions and recommendations}

\section{Ghost fishing}

Issue and policy. Presently, a large knowledge gap exists regarding effects of ghost fishing. While there has been some progress in documenting the frequency of loss from passive gear such as gillnets, little is known about loss from active gears; effective methodology to estimate the persistence of types of 
gear such as trawl nets has yet to be developed (Gilman et al. 2013). While it would be optimal to switch all gear to more biodegradable materials, synthetic materials will continue to be used within fisheries for the foreseeable future. This is an issue that has been highlighted in policy by the Food and Agriculture Organization (FAO), who recommend the identification, quantification and reduction of mortality caused by ghost fishing by implementing this into fisheries management plans, increasing scientific information and developing mitigation strategies; but this appears still to be in its infancy (Gilman et al. 2013). This is also reflected in mandates within the International Maritime Organisation (IMO) and International Convention for Prevention of Pollution from Ships (MARPOL Annex V) (Stelfox et al. 2016).

Need for a global database and spatial hotspot identification. Undoubtedly a common global metadatabase recording the spatial distribution and abundance of possible entangling ghost gear as well as incidences of marine turtle entanglement incorporating a unit of effort metric would assist in quantifying the mortality due to ghost gear that is needed to inform policy (Nelms et al. 2016). A recent global review (dominated by the Atlantic and Pacific oceans) on marine megafauna by Stelfox et al. (2016) reported a total of 5400 individuals of 40 species that had been associated with ghost gear between 1997 and 2015. They suggested this was a great underestimate due to lack of capacity to record incidence. Such data could feed into one of the major research priorities emphasised by respondents; modelling spatio-temporal hotspots of entanglement. An innovative study by Wilcox et al. (2013) used beach clean data and models of ocean drift to map the spatial degree of threat posed by ghost nets for marine turtles in northern Australia and map areas of high risk. With the input of more specific marine location data on ghost gear and the advocacy of the use of ever improving modelling, this could provide a powerful tool in the future.

\section{Education and stakeholder engagement}

Local initiative to reduce debris causing entanglement. On a more local and regional scale, many initiatives are being brought into place to encourage a reduction in the amount of ghost gear/plastic debris entering the ocean and combat discarding at sea by working closely with community education and engagement; another highlighted topic by our re- spondents. There are numerous examples: the sea turtle conservation program in Bonaire has started a 'Fishing Line Project' (www.bonaireturtles.org/wpp/ what-we-do/fishing-line-project) working with volunteers to train them on how to remove discarded line and nets from coral reefs, and the Zoological Society of London's 'Net-works' (www.net-works.com) initiative has established a supply chain for discarded fishing nets from artisanal fishing communities in the Philippines to a carpet manufacturing company. With further replication of such community-based projects and stakeholder engagement, especially with artisanal fisheries awareness, the potential exists to start targeting hotspots of marine vertebrate entanglement directly.

Stranding networks training. Another set of stakeholders which will be important to engage are stranding networks. Responses to entangled turtles can often be slow, and respondents commented that many are not trained in the correct protocols to safely remove entangling materials. If stranding networks were fully trained in a standardised protocol for removal, the techniques could then be passed on through educational training programmes to the fishing community, quickening the response to such incidences. This is already beginning to happen for bycatch cases; Sicilian fisherman now actively volunteer to take part in the rescue of turtles in difficulty and are trained in contacting the competent authorities for the transfer of turtles to the nearest recovery centres. This level of involvement by workers in the fishery sector was stressed and encouraged through both effective education activity and specific targeted study campaigns (Russo et al. 2014).

\section{Future research avenues into marine turtle entanglement}

Respondents raised the issue of post-release mortality and the importance of behavioural research into the interactions between marine turtles and potential entangling materials present in the marine environment. The prominence of this has been emphasised within other taxa; for example, postrelease mortality can result from long-term chronic effects of injuries in pinnipeds even after the entanglement has been removed (McIntosh et al. 2015). Furthermore, it has been argued that some colonial seabirds released from entangling plastic would not survive without human intervention (Votier et al. 2011). 
To validate the success of release protocols after entanglement incidents (as mentioned above), techniques could be employed from other areas of marine turtle research. Satellite telemetry has already been used in a multitude of ways to provide information on conservation issues facing marine turtles; a number of studies have used this technique to consider post-release mortality after bycatch fisheries interactions (reviewed in Jeffers \& Godley 2016). Deploying tagged turtles that have been involved in entanglements could aid in the understanding of survival after these events as well as simultaneously providing information on the location of sea turtles, feeding into information on entanglement hotspots to target mitigation actions. The benefits of utilising such techniques have been illustrated in other endangered species facing entanglement, such as studying mortality of silky sharks Carcharhinus falciformis in the Indian Ocean; estimates derived from satellite tracking showed that mortality due to entanglement was 5 to 10 times that of known bycatch mortality and provided evidence for a call advising immediate management intervention (Filmalter et al. 2013).

Other research methods and ideas could be modified from the study of plastic debris ingestion by sea turtles. Studies are currently underway to understand the selective mechanisms that lead to ingestion of plastic pieces (Schuyler et al. 2014, Nelms et al. 2016). For instance, a study by Santos et al. (2016) used Thayer's law of countershading to assess differences in the conspicuousness of plastic debris to infer the likelihood that visual foragers (sea turtles) would detect and possibly ingest the plastic fragments. Similar studies could be conducted to comprehend the underlying behavioural and physiological mechanisms that influence turtles to approach potential entangling materials when encountering them within the marine environment.

Similarly, comprehending how important the level of biofouling on this synthetic debris is in contributing to the likelihood of entanglement will be important. Total fish catches by monofilament gillnets in Turkey was lower, as a result of accumulating detritus and biofouling increasing the visibility of the nets in the water column (Ayaz et al. 2006). Furthermore, the level of biofouling could indicate the age of ghost gear entangling marine turtles. Retrieved lost/discarded fishing gears are usually found fouled by macro-benthic organisms, so if a relationship between soak time and biofouling level could be established, these organisms could provide a valid methodology to age the gear and enable better esti- mates of 'catches' made by the respective net (Saldanha et al. 2003).

Finally, it will be important to undertake demographic studies, calculating rates of entanglement, especially for specific populations that are known to be particularly vulnerable to a combination of other anthropogenic threats. For species such as pinnipeds, which are less elusive (hauling out on land) than marine turtles, the literature describes different methods. For example, a proportion derived from a count of entangled individuals from a sub-sample or an estimate of the total population (Raum-Suryan et al. 2009, McIntosh et al. 2015), or more recently, the use of mixed-effects models to obtain a prediction of the total number of seals entangled per year, by examining changes in entanglement rates over time and the potential drivers of these detected trends (McIntosh et al. 2015). However, this can only be achieved if reporting and recording such incidences in marine turtles improves in efficacy and standardisation.

\section{CONCLUSIONS}

Further research may show that the issue is more one of animal welfare than of substantive conservation concern to many marine turtle populations. It is clear, however, that entanglement with anthropogenic plastic materials such as discarded fishing gear and land-based sources is an under-reported and under-researched threat to marine turtles. Collaboration among stakeholder groups such as strandings networks, fisheries and the scientific community will aid in providing mitigating actions by targeting the issue of ghost fishing, engaging in education and producing urgently needed research to fill knowledge gaps.

Acknowledgements. The authors thank all respondents of the questionnaires for their invaluable knowledge and insights regarding this issue. We are grateful to Karen Eckert of WIDECAST for granting access to turtle graphics. E.M.D. received generous support from Roger de Freitas, the Sea Life Trust and the University of Exeter. B.J.G. and A.C.B. received support from NERC and the Darwin Initiative, and B.J.G. and P.K.L. were funded by a University of Exeter-Plymouth Marine Laboratory collaboration award which supported E.M.D. We acknowledge funding to T.S.G. from the EU Seventh Framework Programme under Grant Agreement 308370, and P.K.L. and T.S.G. received funding from a NERC Discovery Grant (NE/L007010/1). This work was approved by the University of Exeter, CLES ethics committee (Ref. 2017/1572). The manuscript was greatly improved by the input of the editor and 2 anonymous reviewers. 


\section{LITERATURE CITED}

Anderson RC, Zahir H, Jauharee R, Sakamoto T, Sakamoto I, Johnson G (2009) Entanglement of live ridley turtles Lepidochelys olivacea in ghost nets in the equatorial Indian Ocean. Presented at the fifth session of the Indian Ocean Tuna Commission (IOTC) Working Party on Ecosystems and Bycatch, 12-14 October 2009, Mombasa

Ayaz A, Acarli D, Altinagac U, Ozekinci U, Kara A, Ozen O (2006) Ghost fishing by monofilament and multifilament gillnets in Izmir Bay, Turkey. Fish Res 79:267-271

Balazs GH (1985) Impact of ocean debris on marine turtles: entanglement and ingestion. In: Shomura RS, Yoshida HO (eds) Proceedings of the workshop on the fate and impact of marine debris, 27-29 November 1984, Honolulu, HI. NOAA Tech Memo NMFS-SWFC-54. US Department of Commerce, Washington, DC, p 387-429

Barnes DKA, Galgani F, Thompson RC, Barlaz M (2009) Accumulation and fragmentation of plastic debris in global environments. Philos Trans R Soc B 364:19851998

* Barreiros JP, Raykov VS (2014) Lethal lesions and amputation caused by plastic debris and fishing gear on the loggerhead turtle Caretta caretta (Linnaeus, 1758). Three case reports from Terceira Island, Azores (NE Atlantic). Mar Pollut Bull 86:518-522

Barrios-Garrido H, Petit-Rodriguez MJ, Moreno E, Wildermann N (2013) Ghost nets: a new hazard to sea turtles in the Gulf of Venezuela. In: Tucker T, Belskis L, Panagopoulou A, Rees AL and others (eds) Proc 33 ${ }^{\text {rd }}$ Annu Symp Sea Turtle Biology and Conservation, 5-8 Feb 2013, Baltimore, MD. NOAA Tech Memo NMFS-SEFSC645. Southeast Fisheries Science Center, Miami, FL, p 89

Bentivegna F (1995) Endoscopic removal of polyethylene cord from a loggerhead turtle. Mar Turtle Newsl 71:5

Blasi MF, Mattei D (2017) Seasonal encounter rate, life stages and main threats to the loggerhead sea turtle (Caretta caretta) in the Aeolian Archipelago (southern Thyrrenian Sea). Aquat Conserv 27:617-630

Bolten AB (2003) Variation in sea turtle life history patterns: neritic vs. oceanic developmental stages. In: Lutz PL, Musick JA, Wyneken J (eds) The biology of sea turtles, Vol 2. CRC Press, Boca Raton, FL, p 243-257

Burgman M, Carr A, Godden L, Gregory R, McBride M, Flander L, Maguire L (2011a) Redefining expertise and improving ecological judgment. Conserv Lett 4:81-87

* Burgman MA, McBride M, Ashton R, Speirs-Bridge A and others (2011b) Expert status and performance. PLOS ONE 6:e22998

* Camedda A, Marra S, Matiddi M, Massaro G and others (2014) Interaction between loggerhead sea turtles (Caretta caretta) and marine litter in Sardinia (Western Mediterranean Sea). Mar Environ Res 100:25-32

Casale P (2011) Sea turtle by-catch in the Mediterranean. Fish Fish 12:299-316

* Casale P, Affronte M, Insacco G, Freggi D and others (2010) Sea turtle strandings reveal high anthropogenic mortality in Italian waters. Aquat Conserv 20:611-620

Casale P, Freggi D, Paduano V, Oliverio M (2016) Biases and best approaches for assessing debris ingestion in sea turtles, with a case study in the Mediterranean. Mar Pollut Bull 110:238-249

Chaloupka M, Work TM, Balazs GH, Murakawa SKK, Morris $\mathrm{R}(2008)$ Cause-specific temporal and spatial trends in green sea turtle strandings in the Hawaiian Archipelago
(1982-2003). Mar Biol 154:887-898

Chatto R (1995) Sea turtles killed by flotsam in northern Australia. Mar Turtle Newsl 69:17-18

* Davies RWD, Cripps SJ, Nickson A, Porter G (2009) Defining and estimating global marine fisheries bycatch. Mar Policy 33:661-672

Elaine AI, Seaman CA (2007) Likert scales and data analyses. Qual Prog 40:64-65

Elo S, Kyngäs H (2008) The qualitative content analysis process. J Adv Nurs 62:107-115

Epperly SP, Braun J, Chester AJ, Cross FA, Merriner JV, Tester PA, Churchill JH (1996) Beach strandings as an indicator of at-sea mortality of sea turtles. Bull Mar Sci 59:289-297

* Filmalter JD, Capello M, Deneubourg JL, Cowley PD, Dagorn L (2013) Looking behind the curtain: quantifying massive shark mortality in fish aggregating devices. Front Ecol Environ 11:291-296

Finkbeiner EM, Wallace BP, Moore JE, Lewison RL, Crowder LB, Read AJ (2011) Cumulative estimates of sea turtle bycatch and mortality in USA fisheries between 1990 and 2007. Biol Conserv 144:2719-2727

Francke DL, Balazs GH, Brunson S, Nurzia Humburg I and others (2014) Marine turtle strandings in the Hawaiian Islands January-December 2013. NOAA Pacific Islands Fisheries Science Centre Internal Report IR-14-003. PIFSC, Honolulu, HI

Gall SC, Thompson RC (2015) The impact of debris on marine life. Mar Pollut Bull 92:170-179

* Gardner B, Sullivan PJ, Morreale SJ, Epperly SP (2008) Spatial and temporal statistical analysis of bycatch data: patterns of sea turtle bycatch in the North Atlantic. Can J Fish Aquat Sci 65:2461-2470

Gilman EL (2011) Bycatch governance and best practice mitigation technology in global tuna fisheries. Mar Policy 35:590-609

* Gilman E, Suuronen P, Hall M, Kennelly S (2013) Causes and methods to estimate cryptic sources of fishing mortality. J Fish Biol 83:766-803

Gilman E, Chopin F, Suuronen P, Kuemlangan B (2016) Abandoned, lost and discarded gillnets and trammel nets. Methods to estimate ghost fishing mortality, and status of regional monitoring and management. FAO Fisheries and Aquaculture Technical Paper No. 600. FAO, Rome

Good TP, June JA, Etnier MA, Broadhurst G (2010) Derelict fishing nets in Puget Sound and the Northwest Straits: patterns and threats to marine fauna. Mar Pollut Bull 60: 39-50

*Hamann M, Godfrey M, Seminoff J, Arthur K and others (2010) Global research priorities for sea turtles: informing management and conservation in the 21st century. Endang Species Res 11:245-269

*Hamann M, Grech A, Wolanski E, Lambrechts J (2011) Modelling the fate of marine turtle hatchlings. Ecol Modell 222:1515-1521

* Hart KM, Mooreside P, Crowder L (2006) Interpreting the spatio-temporal patterns of sea turtle strandings: going with the flow. Biol Conserv 129:283-290

* Hunt KE, Innis CJ, Merigo C, Rolland RM (2016) Endocrine responses to diverse stressors of capture, entanglement and stranding in leatherback turtles (Dermochelys coriacea). Conserv Physiol 4:cow022

Innis C, Merigo C, Dodge K, Tlusty M and others (2010) Health evaluation of leatherback turtles (Dermochelys 
coriacea) in the northwestern Atlantic during direct capture and fisheries gear disentanglement. Chelonian Conserv Biol 9:205-222

* Jambeck JR, Geyer R, Wilcox C, Siegler TR and others (2015) Plastic waste inputs from land into the ocean. Science 347:768-771

Jeffers VF, Godley BJ (2016) Satellite tracking in sea turtles: How do we find our way to the conservation dividends? Biol Conserv 199:172-184

Jensen MP, Abreu-Grobois FA, Frydenberg J, Loeschcke V (2006) Microsatellites provide insight into contrasting mating patterns in arribada vs. non-arribada olive ridley sea turtle rookeries. Mol Ecol 15:2567-2575

* Jensen M, Limpus C, Whiting S, Guinea M and others (2013) Defining olive ridley turtle Lepidochelys olivacea management units in Australia and assessing the potential impact of mortality in ghost nets. Endang Species Res 21: 241-253

Koch V, Nichols WJ, Peckham H, de la Toba V (2006) Estimates of sea turtle mortality from poaching and bycatch in Bahía Magdalena, Baja California Sur, Mexico. Biol Conserv 128:327-334

Laist DW (1987) Overview of the biological effects of lost and discarded plastic debris in the marine environment. Mar Pollut Bull 18:319-326

Lawson TJ, Wilcox C, Johns K, Dann P, Hardesty BD (2015) Characteristics of marine debris that entangle Australian fur seals (Arctocephalus pusillus doriferus) in southern Australia. Mar Pollut Bull 98:354-357

López-Jurado LF, Varo-Cruz N, Lopez-Suarez P (2003) Incidental capture of loggerhead turtles (Caretta caretta) on Boa Vista (Cape Verde Islands). Mar Turtle Newsl 101: 14-16

Macfadyen G, Huntington T, Cappell R (2009) Abandoned, lost or otherwise discarded fishing gear. UNEP Regional Seas Reports and Studies No. 185, FAO Tech Pap No. 523. FAO, Rome

Martin TG, Burgman MA, Fidler F, Kuhnert PM , Low-Choy S, McBride M, Mengersen K (2012) Eliciting expert knowledge in conservation science. Conserv Biol 26: 29-38

Matsuoka T, Nakashima T, Nagasawa N (2005) A review of ghost fishing: scientific approaches to evaluation and solutions. Fish Sci 71:691-702

Mazaris AD, Fiksen $\varnothing$, Matsinos YG (2005) Using an individual-based model for assessment of sea turtle population viability. Popul Ecol 47:179-191

McIntosh RR, Kirkwood R, Sutherland DR, Dann P (2015) Drivers and annual estimates of marine wildlife entanglement rates: a long-term case study with Australian fur seals. Mar Pollut Bull 101:716-725

McMahon C, Bradshaw C, Hays G (2007) Satellite tracking reveals unusual diving characteristics for a marine reptile, the olive ridley turtle Lepidochelys olivacea. Mar Ecol Prog Ser 329:239-252

Meager JJ, Limpus CJ (2012) Marine wildlife stranding and mortality database annual report 2011. III. Marine turtle. Conservation Technical and Data Report 2012. Department of Environment and Heritage Protection, Brisbane

Moore E, Lyday S, Roletto J, Litle K and others (2009) Entanglements of marine mammal and sea birds in central California and the north-west coast of the United States 2001-2005. Mar Pollut Bull 58:1045-1051

MSFD GES Technical Subgroup on Marine Litter (2011) Marine litter: technical recommendations for the imple- mentation of MSFD requirements. European Commission Joint Research Centre and Institute for Environment and Sustainability, Luxembourg doi:10.2788/92438

Nelms SE, Duncan EM, Broderick AC, Galloway TS and others (2016) Plastic and marine turtles: a review and call for research. ICES J Mar Sci 73:165-181

Newing H (2011) Conducting research in conservation: social science methods and practice. Routledge, New York, NY

K Orós J, Montesdeoca N, Camacho M, Arencibia A, Calabuig $P$ (2016) Causes of stranding and mortality, and final disposition of loggerhead sea turtles (Caretta caretta) admitted to a wildlife rehabilitation center in Gran Canaria Island, Spain (1998-2014): a long-term retrospective study. PLOS ONE 11:e0149398

Polovina JJ, Balazs GH, Howell EA, Parker DM, Seki MP, Dutton PH (2004) Forage and migration habitat of loggerhead (Caretta caretta) and olive ridley (Lepidochelys olivacea) sea turtles in the central North Pacific Ocean. Fish Oceanogr 13:36-51

Kaum-Suryan KL, Jemison LA, Pitcher KW (2009) Entanglement of Steller sea lions (Eumetopias jubatus) in marine debris: identifying causes and finding solutions. Mar Pollut Bull 58:1487-1495

* Rees AF, Al Saady S, Broderick AC, Coyne MS, Papathanasopoulou N, Godley BJ (2010) Behavioural polymorphism in one of the world's largest populations of loggerhead sea turtles Caretta caretta. Mar Ecol Prog Ser 418: 201-212

* Rees AF, Alfaro-Shigueto J, Barata PCR, Bjorndal KA and others (2016) Are we working towards global research priorities for management and conservation of sea turtles? Endang Species Res 31:337-382

Remie S, Mortimer JA (2007) First records of olive ridley turtles (Lepidochelys olivacea) in Seychelles. Mar Turtle Newsl 117:9

Russo G, Di Bella C, Loria GR, Insacco G, Palazzo P, Violani C, Zava B (2014) Notes on the influence of human activities on sea chelonians in Sicilian waters. J Mt Ecol 7(Suppl):37-41

* Ryan PG, Cole G, Spiby K, Nel R, Osborne A, Perold V (2016) Impacts of plastic ingestion on post-hatchling loggerhead turtles off South Africa. Mar Pollut Bull 107: $155-160$

* Saldanha HJ, Sancho G, Santos MN, Puente E and others (2003) The use of biofouling for ageing lost nets: a case study. Fish Res 64:141-150

Santos AJB, Bellini C, Bortolon LF, Coluchi R (2012) Ghost nets haunt the olive ridley turtle (Lepidochelys olivacea) near the Brazilian Islands of Fernando de Noronha and Atol das Rocas. Herpetol Rev 43:245-246

Santos RG, Andrades R, Boldrini MA, Martins AS (2015) Debris ingestion by juvenile marine turtles: an underestimated problem. Mar Pollut Bull 93:37-43

* Santos RG, Andrades R, Fardim LM, Martins AS (2016) Marine debris ingestion and Thayer's law - the importance of plastic color. Environ Pollut 214:585-588

Sasso CR, Epperly SP (2007) Survival of pelagic juvenile loggerhead turtles in the open ocean. J Wildl Manag 71: 1830-1835

Schuyler Q, Hardesty BD, Wilcox C, Townsend K (2014) Global analysis of anthropogenic debris ingestion by sea turtles. Conserv Biol 28:129-139

Smolowitz RJ (1978) Lobster, Homarus americanus, trap design and ghost fishing. Mar Fish Rev 40:59-67 
Stelfox M, Hudgins J (2015) A two year summary of turtle entanglements in ghost gear in the Maldives. Indian Ocean Turtle Newsletter 22:14-20

Stelfox M, Hudgins J, Sweet M (2016) A review of ghost gear entanglement amongst marine mammals, reptiles and elasmobranchs. Mar Pollut Bull 111:6-17

Tasker M, Camphuysen CJ, Cooper J, Garthe S, Montevecchi WA, Blaber SJM (2000) The impacts of fishing on marine birds. ICES J Mar Sci 57:531-547

Thompson RC, Olsen Y, Mitchell RP, Davis A and others (2004) Lost at sea: Where is all the plastic? Science 304: 838

Vegter A, Barletta M, Beck C, Borrero J and others (2014) Global research priorities to mitigate plastic pollution impacts on marine wildlife. Endang Species Res 25: 225-247

Votier SC, Archibald K, Morgan G, Morgan L (2011) The use of plastic debris as nesting material by a colonial seabird and associated entanglement mortality. Mar Pollut Bull 62:168-172

Editorial responsibility: Rory Wilson,

Swansea, UK
Wallace BP, DiMatteo AD, Hurley BJ, Finkbeiner EM and others (2010a) Regional management units for marine turtles: a novel framework for prioritizing conservation and research across multiple scales. PLOS ONE 5:e15465

*Wallace BP, Lewison RL, McDonald SL, McDonald RK and others (2010b) Global patterns of marine turtle bycatch. Conserv Lett 3:131-142

White D (2006) Marine debris in Northern Territory waters 2004. WWF Australia, Sydney

Wilcox C, Hardesty BD, Sharples R, Griffin DA, Lawson TJ, Gunn R (2013) Ghostnet impacts on globally threatened turtles, a spatial risk analysis for northern Australia. Conserv Lett 6:247-254

Wilcox C, Heathcote G, Goldberg J, Gunn R, Peel D, Hardesty BD (2015) Understanding the sources and effects of abandoned, lost, and discarded fishing gear on marine turtles in northern Australia. Conserv Biol 29:198-206

Whong SL, Ngadi N, Abdullah TAT, Inuwa IM (2015) Current state and future prospects of plastic waste as source of fuel: a review. Renew Sustain Energy Rev 50:1167-1180

Submitted: February 22, 2017; Accepted: September 22, 2017 Proofs received from author(s): November 28, 2017 